\title{
A New Innovative Method of Teaching Foundation Design
}

\section{Gilead Duvshani}

School of Architecture, Ariel University, Ariel, Israel

\section{Email address:}

gileadu@netvision.net.il

\section{To cite this article:}

Gilead Duvshani. A New Innovative Method of Teaching Foundation Design. Science Journal of Education. Vol. 6, No. 2, 2018 , pp. $71-75$. doi: $10.11648 /$ j.sjedu.20180602.14

Received: January 12, 2018; Accepted: March 13, 2018; Published: May 23, 2018

\begin{abstract}
Study aim. In this paper I will argue and discuss a teaching process of fundamental design. When discussing initial instruction of basic tools for design thinking, I find it most appropriate to begin with a method that belongs to the world of art [1]. Method. In my experience, when studies are launched with planning-oriented thinking as their basis, it is far more difficult to subsequently adopt conceptual thinking. By contrast, when storytelling, poetics, and conceptualizations are introduced at the outset as the foundation of design work, the result is a stable infrastructure for subsequent development of planning-oriented thinking. These observations encouraged me to develop a joint freshman program for all design departments when I served as Dean of the Faculty of Design at the Holon Institute of Technology. Until then, departments conducted separate programs that began emphasizing their particular respective professional principles as early as the first year of each program. By contrast, the joint first-year program established students' common foundation of theoretical conceptual thinking and initial design language tools of expression concerning line, composition, and form.
\end{abstract}

Keywords: 2D, Metaphor, Material, 3D, Composition, Imagery, Line

\section{Introduction}

Over the years, design curators and educators have wrestled with these questions in countless work teams and at countless meetings, in an attempt to define design instruction content, structure, and teaching methods, with due attention to the curriculum as a whole. At times, however, such discussions appear to have as many opinions, outlooks, and proposals as they have participants [2].

The works and credo that I would like to present here were collected and developed as I mentored several classes of students involved in a long-term design studio project. The consequences are based on principles and outlooks gleaned from observation and experience more than from scientific analysis and study, yet these materials reflect the significance of establishing the foundation for further study and additional models for the designer training process.

The principle presented herein, which lies at the basis of my theoretical thinking, originated in the belief that design is a practical art [3]; hence practicality and art play an equal role in the development of a design. A work of art, of course, is a statement by its creator, reflecting the outlook inherent in the story the creator aspires to convey. Yet, realistically speaking, hasn't art also had a practical function throughout history and haven't useful artifacts always been one of the objectives of the artistic process? Despite the substantive difference between artistic and practical thinking, a synthesis of the two should ideally permeate the creative process.

\section{Method}

The course I developed and present here aims to teach students a basic understanding of the reasoning and skills required for formal expression. The course focuses on students' physical and mental worlds, and offers practical experience in developing an idea from idea to formal conception in two and three dimensions, as students learn to translate sources of inspiration into a visual conception.

This course aims to teach students what I call the "basic food groups" of design, comprising topics such as composition, black and white, color, form, material, and, especially, the narrative as a catalyst for creation. The idea, of course, is to lay the foundation for design-oriented thinking, on which many subsequent layers are to be placed. 
The Foundation Design Studio [4] addresses all aspects of design, expands students' comprehension of interdisciplinary connections, and of culture as a whole, and establishes a broad foundation for more advanced and focused design studies:

1. Introduction to basic modes of two-and threedimensional expression.

2. Development of two- and three-dimensional compositions as an expression of students' mental worlds, using black \& white and color systems and materials.

3. Introduction to essential concepts such as line, point, light and shadow, scale, rhythm, proportion, and human motion in space.

4. Understanding formal composition as a means for expressing conceptual thinking.

5. Examining objects; focusing on formal relationships and their messages, and the connection between objects, space, and place.

6. Working with materials to construct conceptual compositions.

7. The object as a cultural representation; the object as an image and symbol of a conceptual system.

8. Human movement in space, and human attitudes toward the environment.

The fundamentals of design presented herein were also conceptualized on an understanding of our contemporary world, a world of variations and rapid change, a world of open-ended systems and unraveling edges, a world that demands feedback and dialogue among the various spheres of knowledge, a world that enables us to break through established constraints and cross delineated boundaries and rigidly-defined areas of professional specialization. This world of globalization and international systems highlights the essential need for authentic definition of individual and community expression.

The above observations, along with reciprocity and transition among various fields of design and their expanding interfaces, have led to the realization that all areas of design have a great deal in common, including a basic way of thinking, speaking and communicating about ideas and messages [5].

\subsection{Results}

Results. These observations, along with reciprocity and transition among various fields of design and their expanding interfaces, have led me to the realization that all areas of design have a great deal in common, including a basic way of thinking, speaking and communicating about ideas and messages, which may be summarized as follows:

Conclusion

1. Design is an artistic act that embodies a statement and a story or narrative.

2. From the outset, fundamental design instruction should prioritize methods that emphasize conceptual, narrative thinking rather than those that develop practical, planning - oriented thinking.
3. There is a basic language common to all fields of design, especially in view of our contemporary world of multi-disciplinary syntheses and integrated systems.

There is a basic language common to all fields of design, especially in view of our contemporary world of multidisciplinary syntheses and integrated systems.

4. The creative process begins with the individual self and develops towards thinking about the community and society. It evolves from conceptual thinking to planning efficiency.

These observations encouraged me to develop a joint freshman program for all design departments when I served as Dean of the Faculty of Design at the Holon Institute of Technology. Until then, departments conducted separate programs that began emphasizing their particular respective professional principles as early as the first year of each program. By contrast, the joint first-year program established students' common foundation of theoretical conceptual thinking and initial design language tools of expression concerning line, composition, and form.

The method of teaching the Foundation Design Studio presented in this paper is designed to be the student's first encounter with the field of design. The course covers basic concepts, the acquisition of basic skills, and the ability to apply the components of design language to express visual creativity.

Each first-year Studio class includes students from all departments and is guided by two curators, each from different media fields, thereby collapsing conventional definitions and sparking discussions that challenge crossdisciplinary boundaries.

The above observations, along with reciprocity and transition among various fields of design and their expanding interfaces, have led to the realization that all areas of design have a great deal in common, including a basic way of thinking, speaking and communicating about ideas and messages.

These observations encouraged me to develop a joint freshman program for all design departments when I served as Dean of the Faculty of Design at the Holon Institute of Technology. Until then, departments conducted separate programs that began emphasizing their particular respective professional principles as early as the first year of each program. By contrast, the joint first-year program established students' common foundation of theoretical conceptual thinking and initial design language tools of expression concerning line, composition, and form.

The method of teaching the Foundation Design Studio presented in this paper is designed to be the student's first encounter with the field of design. The course covers basic concepts, the acquisition of basic skills, and the ability to apply the components of design language to express visual creativity. 


\section{Details}

The self

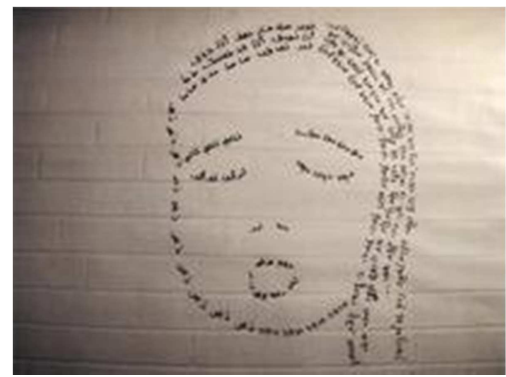

Figure 1. Who am I?

The Line

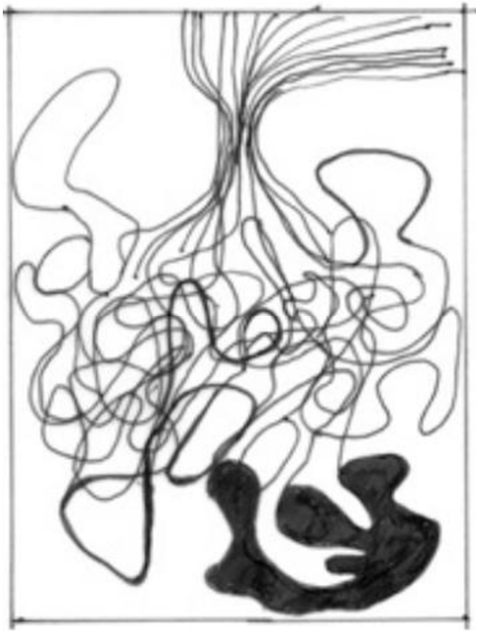

Figure 2. Tell a story as an abstract composition.

From 2 to 3 Dimensions

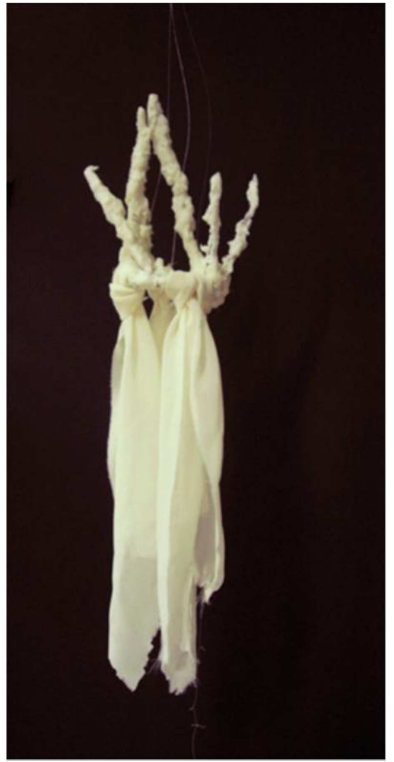

Figure 3. Physical representation of this story in $3 D$

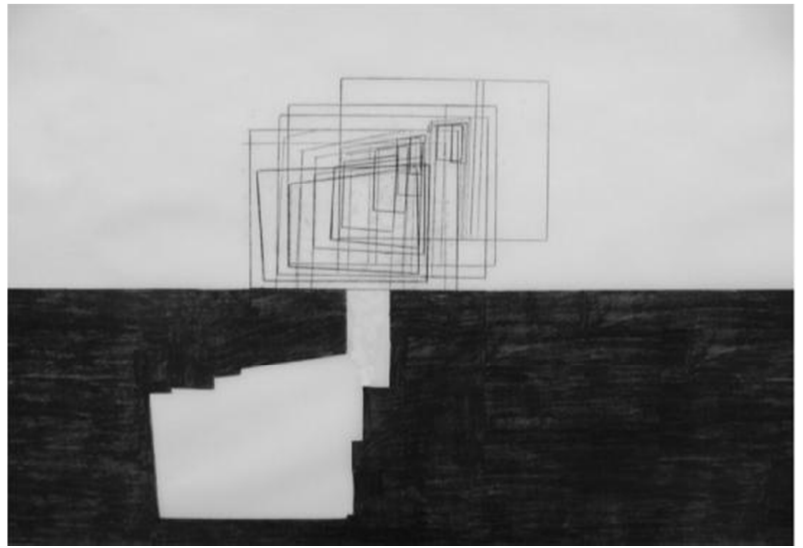

Figure 4. Another story as an abstract composition.

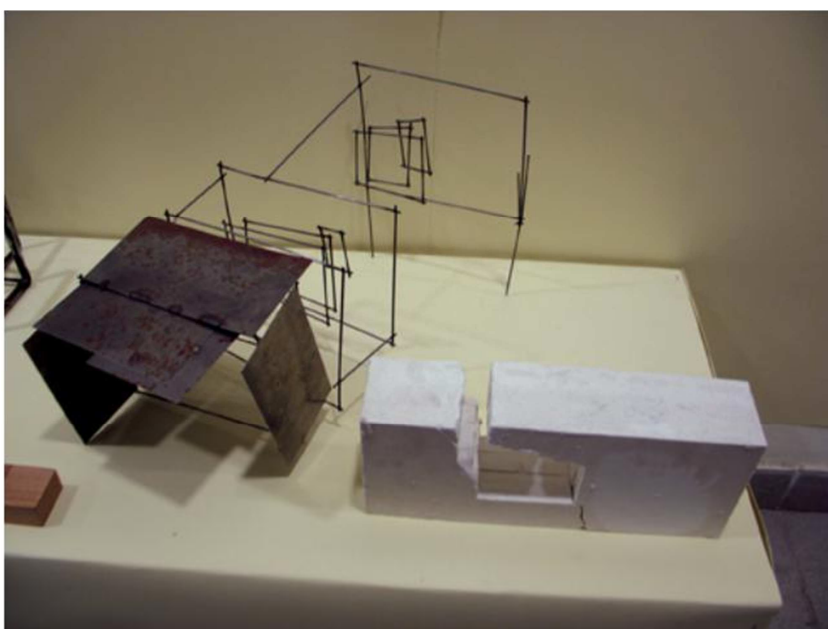

Figure 5. Its representation in $3 D$.

Materials

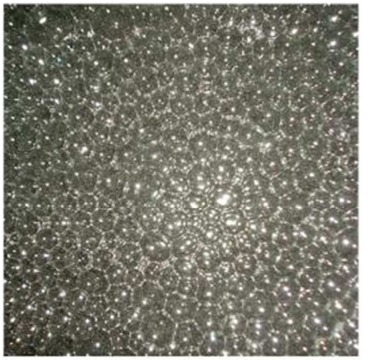

Winter

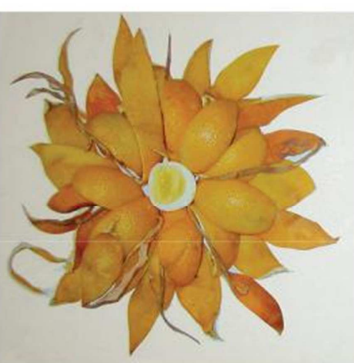

Summer

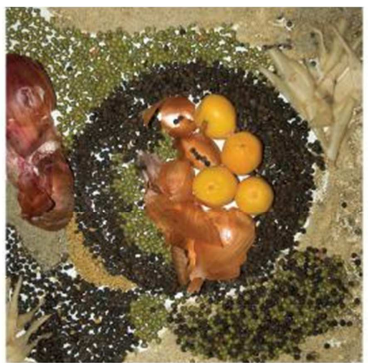

Autumn

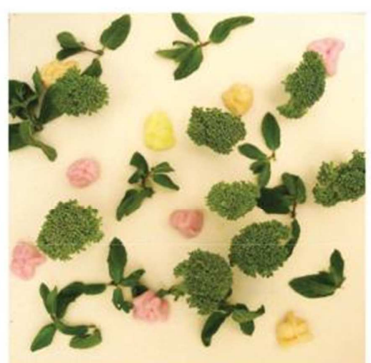

Spring

Figure 6. The four seasons represented through material. 
Metaphor

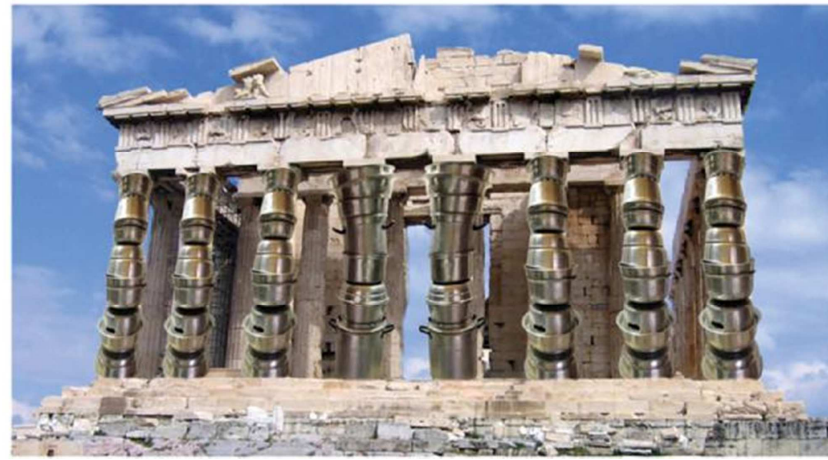

Figure 7. Connecting with a one's realm of imagery.

Conceptual Thinking

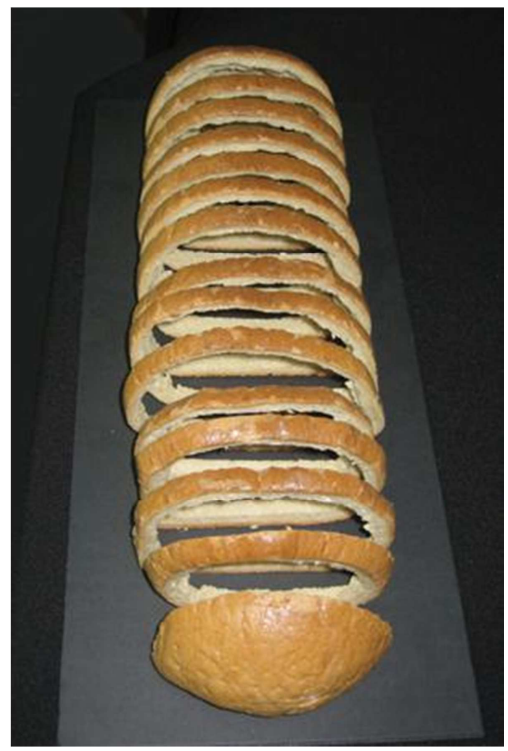

Figure 8. Representing a concept using accessible components.

The Object

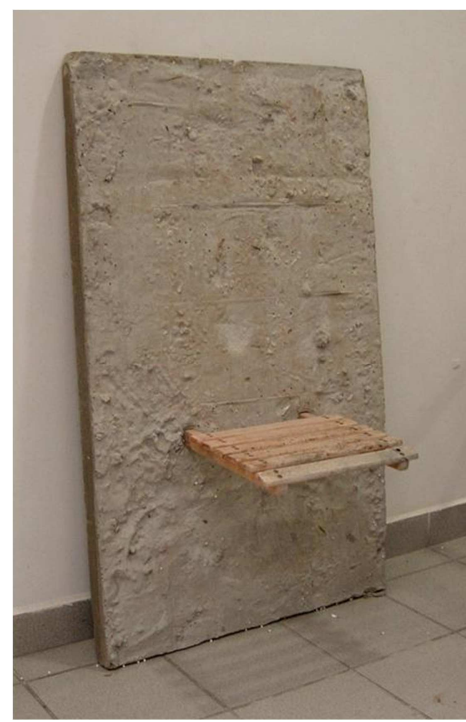

Figure 9. A chair as a product of a story.
Those figures show the process more clearly, especially the different that this paper propose.

The beginning with the knowledge of one self is the first stage to be able to tell a story, than the continuation with a line that express a story is more explicit. The drawing shown in figure 2 is a result of a story, than, from this drawing is developed the 3D in figure 3 . The same with figures 4 and 5 . Figures 6 and 7 show conceptual thinking with materials and with history.

\section{Discussion}

The fundamentals of design presented herein [6] were also conceptualized on an understanding of our contemporary world, a world of variations and rapid change, a world of open-ended systems and unraveling edges, a world that demands feedback and dialogue among the various spheres of knowledge, a world that enables us to break through established constraints and cross delineated boundaries and rigidly-defined areas of professional specialization. This world of globalization and international systems highlights the essential need for authentic definition of individual and community expression.

In a world in which success means marketability and mass-production, designed to generate profit by increasing market shares, and ever-increasing subjugation of new target populations to the hegemony of product lines, isn't there also room and need for the unique personal expression of the individual consumer and the manufacturer or the designer?

Polarization between affluent and impoverished societies, along with the need to protect our limited environmental resources from exploitation and depletion, underline the importance of defining an appropriate system of design instruction.

How do we synthesize these worlds, or, more generally, how do we integrate the dichotomies of the cybernetic world of nameless global communications with our personal worlds? These questions clearly lie at the heart of the design discourse, design programs, and the instructional process. Similarly to Bauhaus curators faced the question of how to integrate the industrial world into art, we face the question of how to integrate the worlds we presently observe with the needs of the individual, community, and society.

It is not our intention to halt progress. One cannot imagine the world today without computers and the Internet, but even in virtual, imaginary cyber world, our sensations and experiences are directly bound with the world of materials, scents, desires, and human contact. As such, in educating future designers [7], it is proper to prioritize discussions of personal concerns in the context of society: Students should learn to use authentic materials and conceptual thinking that may develop in many directions as they synthesize their personal needs for expression with the needs of their society. In my estimation, this site of this synthesis should be a place where discussions of personal and community affairs will flow naturally, revealing the designer's innermost thoughts and values, and impact multifunctional global technological 
systems.

It is not our intention to halt progress [8]. One cannot imagine the world today without computers and the Internet, but even in virtual, imaginary cyber world, our sensations and experiences are directly bound with the world of materials, scents, desires, and human contact. As such, in educating future designers, it is proper to prioritize discussions of personal concerns in the context of society: Students should learn to use authentic materials and conceptual thinking that may develop in many directions as they synthesize their personal needs for expression with the needs of their society. In my estimation, this site of this synthesis should be a place where discussions of personal and community affairs will flow naturally, revealing the designer's innermost thoughts and values, and impact multifunctional global technological systems.

\section{Conclusion}

Nevertheless.

The foundation of art is a statement, a story, a product of conceptual thinking - whereas the foundation of practicality is planning - oriented thinking [9].

The teaching process typically attempts to integrate and combine the distinct methods of art and planning - into a single comprehensive approach. When discussing initial instruction of basic tools for design thinking, I find it most appropriate to begin with a method that belongs to the world of art. In my experience, when studies are launched with planning-oriented thinking as their basis, it is far more difficult to subsequently adopt conceptual thinking. By contrast, when storytelling, poetics, and conceptualizations are introduced at the outset as the foundation of design work, the result is a stable infrastructure for subsequent development of planning-oriented thinking. Similarly, we emphasize the role of the academic institution in teaching design as a venue for intellectual dialogue and as the site of the designer's personal development as a thinking, creative human being with a statement to make. The institution serves as a hothouse that cultivates experiences in theoretical, conceptual thinking as a basis and platform for subsequent study, and a place in which students become acquainted with specialized technical disciplines and internalize the practical characteristics of different types of design.

The path towards creativity is a long, meandering, and somewhat hazy road.

This paper is grounded in the belief that creativity is a function of imagination and the ability to express a personal story [10]. Using visual means to tell a story or a poem evokes free association systems that foster and develop the imagination in the various plastic arts.

Consequently, from the outset, the exercises are designed to develop story-telling skills, as they begin from a personal story, continue through monochrome line and point and progress to the concluding chapter on social attitudes.

The exercises, including those concerning social issues, bring issues and concerns to the foreground in order to develop students' awareness and sensitivity, encourage a critical "eye" and their own personal statement, with less formal attention to any single functional solution.

This paper that described the foundation design course does not offer a recipe for one or two-semester course in the fundamentals of design, nor does it stipulate lesson plans for exercises. Instead, it guides the reader to adopt a specific perspective by cultivating discussions and addressing issues head-on, and as such they serves as a source of inspiration for teachers who develop design studio syllabi and exercises. The purpose is to seeks and promote quality and variety in the marvelous field of design, whose importance to society cannot be overestimated.

\section{References}

[1] D. Pink, A whole new mind, Riverhead Books, 2005.

[2] V. Papanek, The Green Imperative, Thames \& Hudson, London, 1995.

[3] E. Umberto, Architecture Semiotic Function and Sign, Indiana University Press, 1976.

[4] G. Duvshani, Foundation Design Studio, Wasmuth, Berlin, 2010 .

[5] V. Papanek, Design for the Real World, Pantheon Books, New York, 1971.

[6] G. Duvshani, Foundation Design Studio, Wasmuth, Berlin, 2010 .

[7] E. Kieran, Learning in Depth, University of Chicago Press, 2005.

[8] E. Umberto, Architecture Semiotic Function and Sign, Indiana University Press, 1976.

[9] S. Kracauer, The Hotel Lobby, Mass Ornament, Cambridge, Harvard Press, 1995.

[10] G. Duvshani, Foundation Design Studio, Wasmuth, Berlin, 2010. 